\title{
Dermal Substitute for Reconstruction of Large Full Thickness Scalp Defect: a Case of Dermal Regeneration without Removal of the Outer Table of the Skull
}

\author{
Paola Monari $^{1}$ (MD), Ruggero Moro ${ }^{1}$ MD), Daniela Marocolo ${ }^{2}$ (MD), Ausilia Maria \\ Manganoni $^{1}$ (MD), Piergiacomo Calzavara-Pinton ${ }^{1}$ (PH), Giulio Gualdi ${ }^{1}$ (MD) \\ ${ }^{1}$ Department of Dermatology, ASST Spedali Civili, Spedali Civili di Brescia, Brescia Italy \\ ${ }^{2}$ Department of Anatomical Pathology, ASST Spedali Civili, Spedali Civili di Brescia, Brescia Italy
}

*Corresponding Author: Paola Monari, Department of Dermatology, ASST Spedali Civili , Spedali Civili di Brescia, P.le Spedali Civili, 1, 25123 Brescia, Italy.E-mail: paola.monari@libero.it

\begin{abstract}
:
Scalp reconstruction following oncological resection remains today an actual clinical problem. Aggressive neoplasms invading important tissue (soft tissue, galea aponeurotica, periosteum) require specific and safe reconstructive techniques to protect the skull, maintain original surgical margins orientation and preserve adequate tissue for possible adjuvant therapy (radiotherapy for example). For small-medium scalp defects, free flaps or local flaps could permit a good outcome as for aesthetic as for functional point of view. In the other hand, in the case of wide scalp defects skin graft or utilization of dermal substitutes may be taken in consideration only in the presence of adequate wound bed vascularization and an intact periosteum. If the periosteum is removed, i.e. neoplasm invasion, removal of the outer table of the skull is required to have adequate bleeding and vascularization thereby increasing the surgical difficulty. Therefore, at present the surgical options in the absence of pericranium consist of removal of the outer table bone to promote granulation. We describe a case in which a dermal substitute (Matriderm ${ }^{\circledR}$ ) was successfully used for scalp reconstruction after periosteum resection for an aggressive dermatofibrosarcoma protuberans of the scalp, without necessity of burring down the skull.
\end{abstract}

Keywords: dermal substitute, scalp defect, dermatofibrosarcoma protuberans, periosteum removal

\section{INTRODUCTION}

Aggressive neoplasms of the scalp need a wide and deep excision to obtain safe margins and tumor eradication [1]. These considerations sometimes lead to the inclusion of the periosteum as part of wide local excision. The consequence of large surgical excision of the scalp is the exposure of the skull bone with its poor vascularization, therefore a slow granulation and, eventually, a difficult healing by secondary intention. The exposed bone can be covered with local flaps but most often, this option, especially for large flaps, is not without complications (necrosis of the flaps, dehiscence, necessity of general anesthesia, etc.), hence free tissue transfer or use of dermal substitute are the only potential alternatives. Both these techniques have got the advantage to allow rapid coverage of larger surgical defects. On the other hand, they require a well vascularized recipient bed. Consequently, in such cases the outer table of the skull needs to be burred till bleeding is produced [2]. This procedure obviously complicates the reconstructive time, needing a general anesthesia, the presence of a neurosurgeon and increasing the patients' morbidity. We successfully used a dermal substitute (acellular bovine tissue composed of native structurally intact collagen fibrils and elastin - Matriderm ${ }^{\circledR}$ produced by Dr. Suwelack Skin \& Health Care AG, Billerbeck, Germany) directly on the skull for reconstruction of the scalp following the excision of a sarcoma.

\section{CASe RePort}

A 41 years old man was admitted to our clinic for a relapsing dermatofibrosarcoma protuberans of the scalp, previously resected. On a clinical evaluation, the patient showed a 
small nodule on the forehead of about $1 \mathrm{~cm}$ of diameter [Fig.1]. The preoperative nuclear magnetic resonance (NMR) excluded focal bone lesions or focal enhancements of the contrast medium with pathological significance. A large excision with $3 \mathrm{~cm}$ margin including galea aponeurotica was made, with unexpected positive histological findings for persistence of neoplastic cells on the lateral and deep margin [Fig.2]. Then the patient subsequently underwent 3 further excisions until negative histology reported [Fig.3]. The scalp defect was finally of $11 \times 9 \mathrm{~cm}$ with partial lack of the periosteum (exposed skull $3 \times 3 \mathrm{~cm}$ ). We decided to cover the full-thickness defect with a dermal substitute without burring the outer layer of the skull and without general anesthesia. We prepared the Matriderm ${ }^{\circledR}$ ( $2 \mathrm{~mm}$ thick) in accordance with the manufacturer's guidelines and we applied it to fit the surgical defect; Matriderm® was then fixed with sutures. A semi occlusive moist dressing consisting on petroleum gauze was applied under large gauze compresses. The dressing was changed every 5 days paying attention to signs of infection, desiccation of the skull, or regenerated dermis. After 4 week, the dermal regeneration/fibroblast repopulation was complete, even in the absence of periosteum. The patient then underwent the last reconstructive operation which consisted in covering the newly regenerated dermis with a thin split thickness skin graft [Fig.4]. A complete and quick recovery was obtained, and after 2 months no signs of tissue alteration were present at the clinical examination. The patient is currently under oncological follow-up [Fig.5].

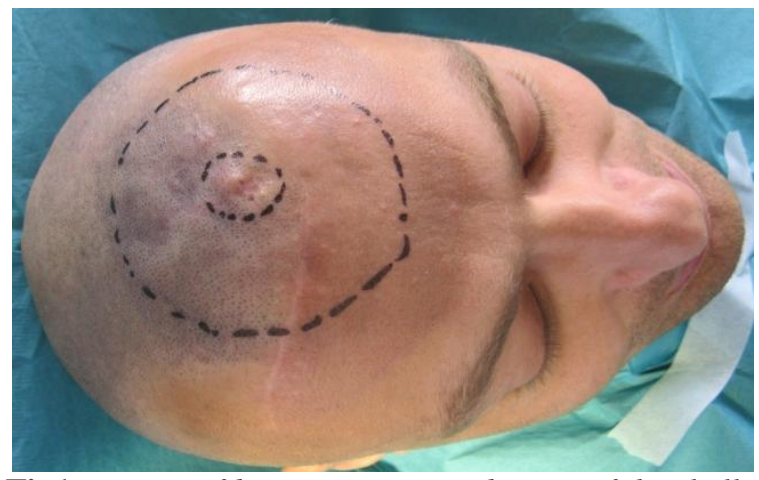

Fig1. Dermatofibrosarcoma protuberans of the skull. Note the inner marker pen sign, corresponding to the tumor actual size, and the outer one, corresponding to the surrounding tissue that needed to be removed for radical excision of this type of neoplasia

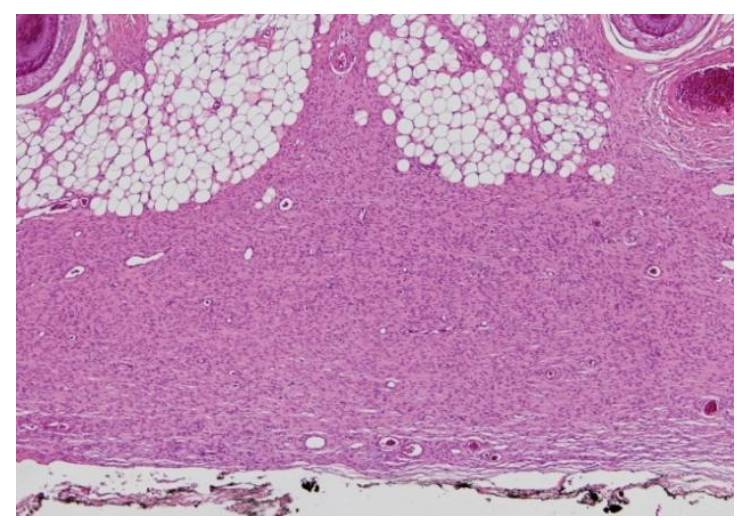

Fig2.Proliferation of spindled cells with elongated nucleus, ill-defined cytoplasm and diffuse infiltration of dermis and subcutaneous tissue.

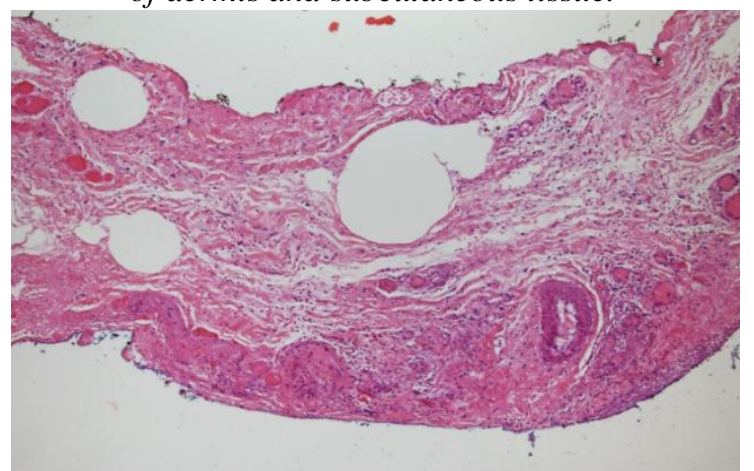

Fig3.Periosteum unscathed from neoplastic invasion.

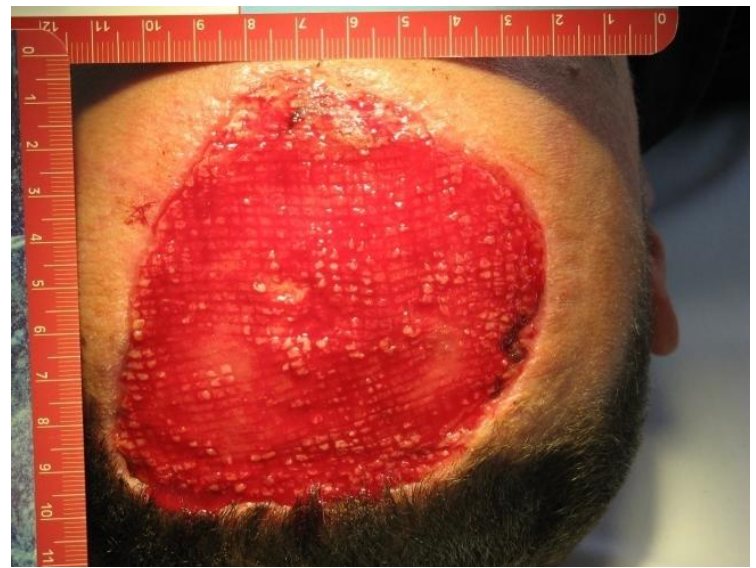

Fig4. After 4 weeks, the newly regenerated dermis is ready to be covered by a thin split thickness skin

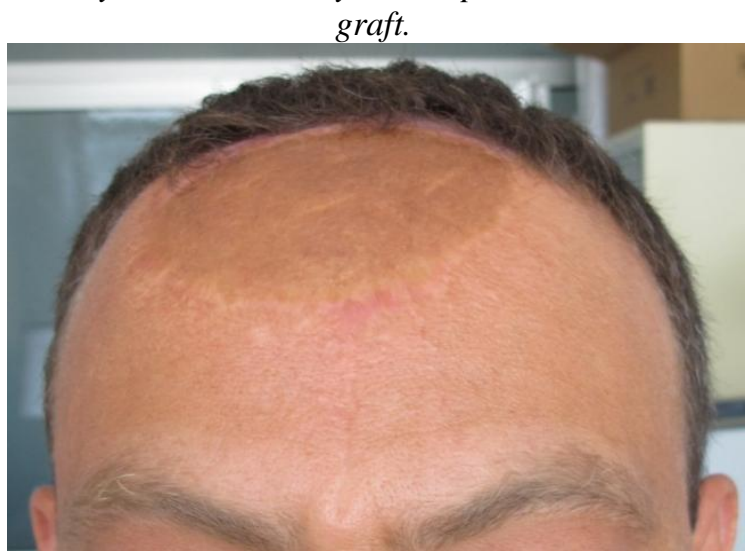

Fig5.Two years' follow-up; there is no sign of relapse of the tumor and the aesthetic outcome is acceptable. 


\section{DISCUSSION}

The scalp's anatomy strongly influences reconstructive surgery especially in case of aggressive neoplasms that require large areas of resection. Since the skin is tethered to the underlying subcutaneous tissue and since the subcutaneous tissue of the scalp is very thin, the surgeon is frequently forced to remove the galea aponeurotica and the periosteum to assure a radical excision of the neoplasm [3]. Therefore, scalp defects remain a surgical challenge since the coverage of the wound should aim to replace the lost tissue with a similar one, to optimize functional and aesthetic outcomes. Furthermore, in case of extensive wounds or in case of the need to observe the original surgical margins of the resection, local flaps are not indicated. In these cases, free tissue transfer becomes a valid option. Skin grafts, alone or after the placement of a dermal substitute, allow for better tumor observation, offer a rapid coverage of the wound, and low morbidity [4]. A major limitation is that split-thickness skin grafts and dermal substitutes need a well vascularized recipient bed to survive because of their high metabolism [5,6]. If the periosteum is absent the vascularization of the underlying intact calvarium is insufficient to allow graft survival. In fact, periosteum is a tissue that need adequate vascularization of the skull, so its lack does not permit one to cover the defect directly with skin graft or dermal substitute for the high risk of necrosis. We successfully covered a scalp, partially lacking in periosteum, with a dermal substitute able to induce fibroblast migration even in the absence of an adequate bed. It is likely that the young age of the patient, the absence of metabolic and vascular disease, and the particular structure of Matriderm ${ }^{\circledR}$ may have contributed to the engraftment of the scaffold and, consequently, to the cellular movement across the wound. Our objective is to proceed with the utilization of this product Matriderm®- increasing the number of patients and therefore increasing our clinical knowledge.

\section{REFERENCES}

[1] Abo Sedira M, Amin AA, Rifaat MA, El-Sebai HI, El-Badawy MA, Aboul Kassem HA.Locally advanced tumors of the scalp: the Egyptian National Cancer Institute experience. J Egypt Natl Canc Inst. 2006 Sep;18(3):250-7

[2] Koenen W, Goerdt S, Faulhaber J. Removal of the outer table of the skull for reconstruction of full-thickness scalp defects with a dermal regeneration template. Dermatol Surg. 2008 Mar;34(3):357-63. Epub 2007 Dec 19.

[3] Komorowska-Timek E, Gabriel A, Bennett DC, Miles D, Garberoglio C, Cheng C,Gupta S. Artificial dermis as an alternative for coverage of complex scalp defects following excision of malignant tumors. Plast Reconstr Surg. 2005 Apr;115(4):1010-7.

[4] Wilensky JS, Rosenthal AH, Bradford CR, Rees RS. The use of a bovine collagen construct for reconstruction of full-thickness scalp defects in the elderly patient with cutaneous malignancy. Ann Plast Surg. 2005 Mar;54(3):297-301.

[5] Corradino B, Lorenzo S D, Leto Barone AA, Maresi E, Moschella F. Reconstruction of full thickness scalp defects after tumour excision in elderly patients: Our experience with Integra((R)) dermal regeneration template. J Plast Reconstr Aesthet Surg. 2009 Jun 18.

[6] Muangman P, Engrav LH, Heimbach DM, Harunari N, Honari S, Gibran NS, Klein MB. Complex wound management utilizing an artificial dermal matrix. Ann Plast Surg. 2006 Aug;57(2):199-202.

Citation: Paola Monari et al. Dermal Substitute for Reconstruction of Large Full Thickness Scalp Defect: a Case of Dermal Regeneration without Removal of the Outer Table of the Skull. ARC Journal of Surgery.2017; 3(1):8-10. doi:dx.doi.org/10.20431/2455-572X.0301003.

Copyright: (C) 2017 Authors. This is an open-access article distributed under the terms of the Creative Commons Attribution License, which permits unrestricted use, distribution, and reproduction in any medium, provided the original author and source are credited. 